\title{
Trust and the doxastic family
}

\author{
Pascal Engel
}

Published online: 12 May 2012

(C) Springer Science+Business Media B.V. 2012

\begin{abstract}
This article examines Keith Lehrer's distinction between belief and acceptance and how it differs from other accounts of belief and of the family of doxastic attitudes. I sketch a different taxonomy of doxastic attitudes. Lehrer's notion of acceptance is mostly epistemic and at the service of his account of the "loop of reason", whereas for other writers acceptance is mostly a pragmatic attitude. I argue, however, that his account of acceptance underdetermines the role that the attitude of trust plays in his analysis of reason.
\end{abstract}

Keywords Belief - Acceptance - Doxastic attitudes · Trust - Reason - K. Lehrer

\section{Lehrer on belief and acceptance}

Keith Lehrer's distinction between belief and acceptance (1983, 1990a, b, 2003) anticipated much later work on the difference between belief and other doxastic attitudes of the same family. Lehrer was one of the first, in contemporary analytic philosophy, to rediscover an insight which goes back at least from the Stoics, the idea that there is a variety of forms of assent, among which belief is only one species. ${ }^{1}$ Acceptance and belief differ not only psychologically but also epistemologically. ${ }^{2}$ I would like here to try to assess Lehrer's contribution, to compare it with others similar distinctions, and to suggest a slightly different way of carving the doxastic nature at its joints.

\footnotetext{
${ }^{1}$ On the different kinds of assent in ancient Stoicism, see e.g., Frede (1987); Barnes (1982). There are indeed a lot of similarities between what the Stoics called sunkatathèsis and what Lehrer calls acceptance.

2 See Cohen (1989, 1992); Bratman (1992); Engel (1998, 1999, 2000); Frankish (2004).

P. Engel ( $\square)$

University of Geneva, Geneva, Switzerland

e-mail: Pascal.Engel@unige.ch
} 
The attitude of acceptance is a central piece in Lehrer's well known internalist and coherentist definition of knowledge. Barring various complexities of the definition, $\mathrm{S}$ knows that $\mathrm{P}$ iff.

(i) $\mathrm{P}$ is true

(ii) $\mathrm{S}$ accepts that $\mathrm{P}$

(iii) $\mathrm{S}$ is personally justified in accepting that $\mathrm{P}$

(iv) $\mathrm{S}$ is justified in accepting that $\mathrm{P}$ on the basis of $\mathrm{S}$ 's evaluation system at $\mathrm{t}$, and if acceptance of $\mathrm{P}$ coheres with that system, and in a way which is undefeated (Lehrer 1990a, p. 26; 1997, p. 44).

Why "acceptance" and not "belief" as in the traditional analysis of knowledge? Because, according to Lehrer, only an attitude which involves more than belief, and the evaluation of one's beliefs, is susceptible to provide the appropriate personal justification required for full blown and undefeated knowledge. Acceptance, like belief, is a functional state, but a second-order one: it has a belief-content as its object, but it is not a belief. It is a meta-level state, involving conscious reflection and reasoning. It is defined in terms of some aim or purpose of a subject, namely the purpose is attaining truth and avoiding error, through reasoning and evaluation of one's own justifications. Belief, in contrast may be defined in terms of a purpose (it "aims" at truth, as one says) but not necessarily (many beliefs are not aimed at truth). Belief involves mostly the processing of information at the first-order level that is not necessarily conscious or available directly to reasoning or inference. I may, for instance, have the information - and therefore in this sense believe-that your phone number is 41223797053 , because it is the number that came up to my mind when your name was mentioned to me, but unless I have manifested my capacity to reason from this belief, I am in no position to evaluate that belief. Or I can learn, hence believe, that the person I have met a few minutes ago just died, but I may not accept it. In these examples the content of the belief and the content of the acceptance are the same, but there are many cases of dissociations where one does not accept what one believes. Thus a racist juror may accept that the black man who is in the box is innocent, although he believes that he is guilty (Lehrer 2000, p. 196).

Lehrer's views on belief and acceptance share a number of features with the views of other authors, but it has also a number of specific features. His distinction between mind and metamind (1990b) resembles Fodor's (1983) distinction between input systems, which are largely automatic, modular and encapsulated and the central system which is slow, holistic and inferentially promiscuous, but it does not coincide with it, since for Fodor it is belief which lends itself to inference and reasoning and to holistic connections, whereas sensory systems and subdoxastic states are not so penetrable to inferences (Stich 1978). Lehrer does not deny that belief can give rise to inferences, but as he points out (2000, p. 211) inference from beliefs can be largely habitual and automatic, just as higher-order evaluation can be habitual and automatic. The distinction has more to do with the conscious character of acceptance.

Neither should Lehrer's distinction be assimilated to Cohen's $(1989,1992)$ and Bratman's (1992) similar distinction. Cohen and Bratman take acceptance to be essentially occurrent, voluntary, associated to conscious acts of judgments, 
motivated by pragmatic reasons and contextual in nature. They both emphasize the pragmatic nature of acceptances, which can occur in the absence of belief (which is a mere feeling on Cohen's view), and which can be entertained for purely practical or prudential reasons (the standard example is the lawyer who believes his client guilty but accepts in court that he is not). Bratman defines acceptance as an attitude which one typically takes in the activity of rational planning, and Cohen defines acceptance as a kind of policy: “To accept that $p$ is to have, or to adopt a policy of deeming, positing, or postulating that $p-$ i.e. of including that proposition or rule among one's premises for deciding what to do or think in a particular context, whether or not one feels it true that p." (Cohen 1992, p. 4). The policy can be adopted for ultimately epistemic reasons, as when one takes something for granted for the sake of future argument, but the adoption of the policy is itself provisional and pragmatic in the sense that it is contextually determined. In contrast Lehrer insists that acceptance is a functional state which is distinct from its possible manifestation as a commitment expressed by a speech act of the form: "Accept that P". So acceptance can be dispositional and need not be voluntary, ${ }^{3}$ although it is functionally related to preferences. Moreover, for Lehrer, acceptance is essentially an epistemic attitude, not a pragmatic one. For Lehrer the meta-doxastic attitude that on has towards $\mathrm{P}$ for practical reasons, hence associated to practical reasoning, is better called preference, which stand to desires in the same relation as the one in which acceptances stand to beliefs (Lehrer 1997, pp. 11, 12). Epistemic acceptances are those which play a role in personal justification: $\mathrm{S}$ is justified in accepting that $\mathrm{P}$ if and only if $\mathrm{P}$ coheres with $\mathrm{S}$ 's evaluation system at $\mathrm{t}$, and if all objections to $\mathrm{P}$ are neutralized. Acceptance is evidence sensitive, belief not necessarily. Acceptance is relatively stable, and it is not contextual in the sense in which pragmatic acceptance is according to Cohen or Bratman. Acceptance that $\mathrm{H}$ introduces a kind of rational equilibrium over rational reflection at a point in time in the sense that rational reflection on the present evidence will not change my acceptance of $\mathrm{H}$ or the degree of probability of $\mathrm{H}$ which is a factor in the acceptance of $\mathrm{H}$ at the present time. Thus if $\mathrm{R}$ is the rational consideration of the evidence for $\mathrm{H}$ at $\mathrm{t}$, and $\mathrm{I}$ accept that $\mathrm{H}$, then the antecedent probability for $\mathrm{H}$ is stable on $\mathrm{R}$, that is $\mathrm{Pt}(\mathrm{H})=\mathrm{Pt}(\mathrm{H} / \mathrm{R})$ (Lehrer 2000 , p. 215). This is not true for belief because belief may arise without evaluation of evidence.

Lehrer's distinction is explicitly drawn for epistemological, not primarily psychological, purposes. Acceptance plays an important role in his "loop" of selftrust, upon which he bases his conception of knowledge (1997, p. 16). His "principle of trustworthiness"- I am trustworthy in what I accept-is the "keystone" of his "loop of reason". Is it justified? I would like to argue here that this depends in large part upon how we understand the attitude of acceptance. I shall first try to show that Lehrer's classification of attitudes has to be refined if it is supposed to be descriptively adequate. I shall then try to apply the lessons of the classification to his account of trust as the foundation of knowledge.

\footnotetext{
${ }^{3}$ Compare here with Frankish (2004), who also has a category of implicit acceptances.
} 


\section{Two systems of doxastic attitudes or one?}

There are a number of ways one can draw the psychological distinction between belief and acceptance and classify these with the family of doxastic attitudes. One can, on the one hand, take belief to be the most general attitude, of which acceptance is a species. ${ }^{4}$ Alternatively one can call "acceptance" the general attitude of holding true or of assenting to a proposition, and take belief to be a subvariety. (Stalnaker 1984, pp. 79-81) But most views imply that belief and acceptance are different functional sates. On the paradigm notion of belief, belief is a dispositional or functional state, involuntary and passive, sensitive to evidence, and inferentially promiscuous, whereas acceptance is most often understood as a conscious mental act, tied to the speech act of assertion, sensitive either to evidence or to pragmatic goals, and expressing a commitment in future doxastic deliberation. Some, however, hold that acceptance can be tacit (Frankish 2004, pp. 94, 95). Others give definitions of belief which are actually very similar to the way acceptance is characterised: "To believe a proposition is to accept it with the aim of thereby believing a truth." (Velleman 2000, p. 251) Where should we draw the line?

A number of mental states share with paradigmatic beliefs some features, but lack others. They seem to deserve the title of "belief" only by courtesy. The list is quite long and its limits are uncertain. Can forgettings, cases in which apparently one loses a belief because it is erased partially from memory, be counted as beliefs? They have sometimes been called "in between believings" (Schwitzgebel 2001). Can "feelings of knowing", such as the "tip of the tongue phenomenon" (Koriat 2000) be included as well? There has been a lot of discussion about the existence of putative "tacit beliefs" which lay dormant within our mind but which manifest themselves when one mentions them, such as my belief that Elephants do not wear pyjamas in the wild (Lycan 1985). More common examples of implicit beliefs lying at the borderline of the territory are racist beliefs, upon which one often acts but which do not surface in assent, and irrational or delusive "beliefs", like those which appear in self-deception. These states have some belief-like features, but lack others. Thus patients affected by the Capgras delusion have belief-like states (they seem to believe that their friends and family have be replaced by impostors), but their "beliefs" are often unresponsive to evidence and to inference, and do not lead, like ordinary beliefs, to characteristic behaviour or actions. Self deceptive "beliefs" are often associated with explicit disavowal, refusal to consider contrary evidence. Other belief-like states, like fears or phobias, have a strong emotional component and a strong behavioural uptake, although they are not sensitive to evidence and to other beliefs. Cohen (1992, p. 5) talks of "belief feelings" or of "creedal feelings" to characterise mental states like hope, fear, expectation or surprise. Gendler (2000) has called "alief" the kind of cognitive state mixed with vertigo in which one finds oneself when walking on the transparent road way above the Grand Canyon. Emotions have, on most views, a cognitive component, but it is hard to disentangle it from the emotion, as the "paradox of fiction" exemplifies: watching an horror

\footnotetext{
4 This is the line taken by Dennett (1978, pp. 300-309) who distinguishes belief, a general dispositional state, from "opinion", which is the product of a verbal assent.
} 
movie you do not believe that what you see on the screen is real, but you feel the emotion of fear nevertheless, which in turn implies the belief that what you see is real (Radford 1975). Imaginings can be described as kinds of beliefs, but can also be described as very unlike believings (Velleman 2000). Some descriptions of religious belief make it dubious that they are beliefs at all. Last but not least, where in this list of "beliefs" should we put degrees of beliefs or "partial beliefs"? Are these a genuine kind of mental state or a mere construct of the Bayesian conception of belief as degree of probability? What is their relationship to "full" belief? The list could be extended. In all these cases, it is debated whether these belief-like states are beliefs or whether they are only belief's bedfellows. ${ }^{5}$

How can we frame a taxonomy which could take into account all the members of the doxastic family? One important framework in recent cognitive psychology is the "dual system" view according to which there are two distinct systems in human cognition, in particular in reasoning, decision making, and learning, characterised respectively by the following general features (Evans and Frankish 2008, p. 16):

\begin{tabular}{ll}
\hline System 1 & System 2 \\
\hline Evolutionarily old & Evolutionarily recent \\
Unconscious, preconscious & Conscious \\
Shared with animals & Uniquely (distinctively) human \\
Implicit knowledge & Explicit knowledge \\
Automatic & Controlled \\
Fast & Slow \\
Parallel & Sequential \\
High capacity & Low capacity \\
Intuitive & Reflective \\
Contextualized & Abstract \\
Pragmatic & Logical \\
Associative & Rule-based \\
Independent of general intelligence & Linked to general intelligence \\
\hline
\end{tabular}

It is tempting to classify credal feelings, "alief", irrational beliefs and dispositional beliefs within System 1 and acceptances within System 2. But this is obviously too quick. A number of properties of paradigm belief features within System 1 have System 2 features and vice versa: inferentially promiscuous, reflective, evidence based. Belief in many ways is, to take up Scanlon's (1998), a "judgment-sensitive" attitude as much as a dispositional state. System 1 is supposed to be strongly modular and System 2 to be distributed and holistic, but a number of writers have argued that System 2 is modular as well (Sperber 2001). Even pragmatic acceptance, of which a number of writers claim that it can occur in the

\footnotetext{
${ }^{5}$ I borrow this expression from Tim Bayne, who suggested it in a talk in January 2011. On the issue whether delusional beliefs are genuine beliefs (and for a positive answer) see Bayne and Pacherie (2005). For the opposing view, see Currie and Ravencroft (2002).
} 
absence of belief, actually depends upon pre-existing beliefs. ${ }^{6}$ So the distinction between the two systems is moot, and the properties which characterise them may well apply to several subsystems which share only partly these properties. Thus some processes in reasoning fit both System 1 and System 2 (Carruthers 2012).

Although there are strong empirical reasons for the existence of different cognitive subsystems having a number of properties of System 1 and of System 2 respectively, there is no reason to suppose that these subsystems all belong either to System 1 or to System 2, hence that the distinction between two types of systems or of processes in the mind corresponds to a natural kind. When it comes to belief, there is reason to think that there is much more continuity between "belief like" and "acceptance like" features than the dual systems view allows. I would like to come back to the alternative - and more classical—picture of a unique, but layered system of doxastic attitudes, with one general category, belief, and a variety of subcategories belonging to that species. This picture has been advanced in recent cognitive psychology for a variety of other mental states. Thus it has been proposed that intentions can be divided into "motor intentions" at a low cognitive level, "intentions-in-action" at the time of execution, and "prior" intentions as plans. (Searle 1983, Pacherie 2000) Similarly we can propose the idea that there are continuous levels of belief, starting at a low level with creedal feelings and dispositional beliefs, moving upwards to degrees of belief and to assents, with judgments and acceptances at the top level. On such a continuous taxonomy it is not clear that there is a real distinction between states of beliefs and states of acceptance. We can start from a minimal characterisation of belief as a mental attitude governed by a norm of truth:

(NT) A belief is correct if and only if it is true ${ }^{7}$

Although this norm governs most beliefs when an agent deliberates reflectively on whether to believe that P (Shah and Velleman 2005), it can nevertheless be argued that it governs also irrational or unconscious belief formation. Contrary to what a number of critics of the truth-norm for belief have argued, the norm need not be an explicit prescription which would regulate every step of belief formation at the intentional level. Thus take irrational beliefs, such as delusions. It has been argued that patients who are victims of such pathologies actually do not believe the things that they seem to believe, but only believe that they believe them and imagine them: their doxastic attitudes are more like hallucinations than like belief (Currie 2000). It seems hard to say that the patients with such monothematic "beliefs" have doxastic attitudes which can be put on a par with beliefs. Indeed the beliefs which

\footnotetext{
6 Thus take Bratman's (1992) example of the prospective builder who accepts that the cost of the house he plans to build will be a certain amount, $\$ 1000$ 000. But what he accepts here is not that the house will cost $\$ 1000000$. What he accepts is that the probability of the estimated cost of $\$ 1000000$ exceeds the estimated cost that he makes. And he makes this estimation just in the way a good Bayesian would do it: by calculating the prior estimated probability, and by taking the conditional probability of the cost given this first estimate. He accepts finally that the probability of the total cost exceeds his prior estimate. But he certainly makes this estimate on the basis of his subjective probabilities. So acceptance here is not identical to a subjective probability, although it is based on one (see on this example Engel 1998).

7 See Shah and Velleman (2005) and Engel (2008).
} 


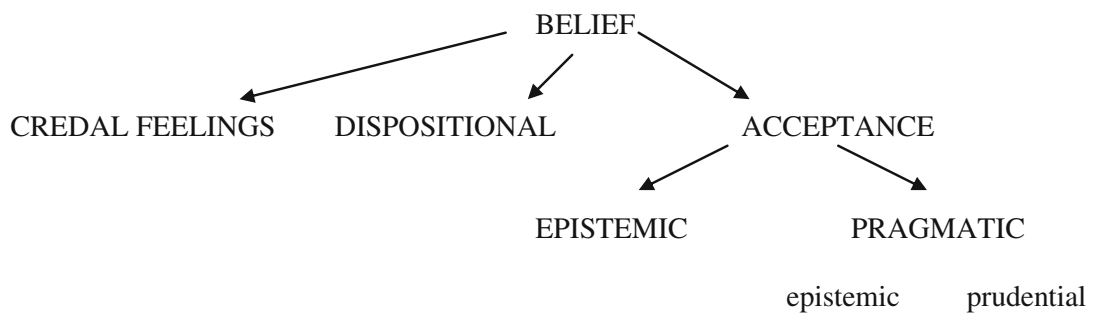

Fig. 1 The divisions of belief

are characteristic of the Capgras delusion are very unlike ordinary belief, but they nevertheless involve a feeling or an emotion of conviction towards a proposition. The state in question may be inferentially insulated and insensitive to evidence, but it is sensitive to the norm of truth (Bayne and Pacherie 2005, p. 183).

On the taxonomy of propositional attitudes sketched here, there is no basic division between belief-like states having features of System 1 and acceptance-like states having features of System 2. Here is only one category of states, belief, which is a form of assent or of holding true, governed by a norm of truth, which can be, in some cases, a mere creedal feeling, or in others a judgement or an acceptance. This does not mean that there are no distinctions and that there is no room for a rational epistemic attitude such as that which Lehrer describes as acceptance. Acceptances in turn can be either epistemic, governed by epistemic reasons and for the sake of theoretical reasoning, or pragmatic and contextual and for the sake of prudence. There is a further subdivision: when they are pragmatic, they can either be governed by epistemic or by practical reasons (Fig. 1).

In what sense is this taxonomy distinct from Lehrer's? It is distinct in that on the present taxonomy, acceptance is a kind of belief and not a separate doxastic attitude, and in that acceptance comes in two forms, epistemic and pragmatic. For Lehrer acceptance, which is distinct from belief, has one form and is essentially epistemic. All of this may be a matter of terminology, and a lot of the literature on acceptance has turned on terminological matters. But the issue is not only terminological, as we shall see when it is applied to the problem of the foundation of reason.

\section{Acceptance and trust}

Acceptance is not merely a psychological attitude. It is also, and foremost, an epistemological and theoretical attitude. It plays a crucial role in what Lehrer calls his principle of trustworthiness:

(T) I am trustworthy in what I accept with the objective of accepting something just in case it is true.

This principle is supposed to be the "keystone" at the basis of knowledge, and because it is self-supporting it is the basis of the "loop of reason". Lehrer (1997, p. 6) gives us the "acceptance argument": 
(1) I accept that P with the aim of truth.

(2) Therefore I am trustworthy in accepting that P.

(3) Therefore I am reasonable in accepting $\mathrm{P}$ with the aim of truth.

The argument raises at least two questions: (a) how is my trustworthiness in accepting that $\mathrm{P}$ supposed to flow from my accepting that $\mathrm{P}$ ? (b) What is the nature of the acceptance which gives rise to trustworthiness? Let us start with the second question. As we saw, Lehrer characterises acceptance in epistemic terms. It is a functional state which is directed towards truth, and leading to inference and reasoning. But although it is theoretical, Lehrer describes it as an act of reasoned choice which is "the freedom to be guided by my acceptances" (Lehrer 2000, p. 219), hence as a kind of act and as a practical attitude which is much similar to what I have called above pragmatic acceptance, although it is governed by epistemic reasons (it aims at truth and knowledge). Indeed the fact that trust is the result of a reasoned choice orientated towards reason and truth does not make it a pragmatic acceptance in the prudential sense, for it is a pragmatic acceptance in the epistemic or theoretical sense, according to the above distinctions. But it involves a choice of the agent, and is in this sense pragmatic nevertheless. Trust too, as it figures in premise (2) of the acceptance argument, is a practical attitude. What is characteristic of the attitude of trust is that it is not, as such, evidentially constrained. But trust, like acceptance, can be more or less, rational. The problem is: can it be rational in a sense which would give us the appropriate bootstrapping in the loop of reason? There is bootstrapping in that to accept that $\mathrm{P}$ is to take oneself to be trustworthy in one's belief that P. Lehrer's idea is to use acceptance as a minimal epistemic attitude which can serve as a lever to obtain knowledge, but without taking it to involve knowledge, for otherwise the strategy would be circular (David 1991). But one may ask: if acceptance is supposed to be the minimal attitude on the way to knowledge, how does one know that one is reasonable? Whether or not reasonableness is supposed to do the trick in levelling knowledge, the sceptic is entitled to ask: how do we know that we are reasonable? To answer this question, Lehrer (1990a) adds the condition of trust. If I accept that P, I must accept that it is for me more reasonable to believe that $\mathrm{P}$ than to believe that not $\mathrm{P}$, and $\mathrm{I}$ do that with the aim of believing the true and avoiding the false. But I must also accept that I am trustworthy about P. As Lehrer says:

I must accept that I am trustworthy as well: that when I accept something, that is a good enough reason for thinking it to be true, so that it is at least more reasonable for me to accept it than to accept its denial. (1990a, p. 122)

The full acceptance argument contains two more steps:

(4) I am reasonable to trust my acceptance that P.

(5) I am reasonable to accept P.

Here the trust condition ("I am worthy of my trust") is a meta-level condition which says that I am trustworthy concerning my acceptances. But, as Lehrer (1997, p. 7) notes, this seems to be the argument from despair: unless I accept my own trustworthiness I cannot respond to the sceptical doubt. It indeed looks perfectly 
circular: my reasonableness presupposes my trust in my reasonableness, but my trust presupposes that I take myself to be reasonable. But, Lehrer tells us that although the sceptic will never be convinced of (2), (2) applies to the acceptance of itself. It is actually a "keystone loop" as he calls it (1997, p. 9) of my claim to know. The loop or the circle is virtuous.

Although trust is here a personal matter the attitude of acceptance is motivated by self-trust. But both the sceptic and the dogmatic are here prone to ask: where does this trust come from? Is it the product of a pure act of faith? Could I accept something for reasons which would fall short of being epistemic or could I accept something for no reason at all, or "for nothing"? Clearly not, and for two reasons. In the first place, I accept only what is worthy of acceptance. So truth is the aim, and it is implicit in Lehrer's argument that one values truth. Lehrer actually argues against instrumentalism (ibid, 56): truth is the ultimate goal and I am not worthy of my trust if I reach truth by pure luck. In the second place I do not ascribe to myself trustworthiness unless I can give reasons for it. As he says: "What makes me trustworthy in what I accept (...) is that I exercise a capacity to accept what is worth accepting. This requires a capacity to discern that the ends that I pursue in acceptance are worth pursuing." (ibid, 56) But this does not come by magic. The capacities are grounded somewhere. My reasons for being a worthy guide to the truth must have something to do with my reliability. ${ }^{8}$

Lehrer is, like a number of other philosophers who have invoked the notions of trust and of acceptance as the basis for reasonableness, ${ }^{9}$ faced to a dilemma: either the notion of acceptance is a pragmatic one, and (unless one sides with pragmatism in holding that theoretical reasons and justifications are reducible to practical ones) it cannot be a basis for reason, or it is an epistemic attitude. If so, it must contain an evidentialist and a reliabilist component. Keith Lehrer admits that acceptance is based on a capacity to accept. $(1997,56)$ What else can this capacity be, if not a disposition to believe that I am trustworthy? Hence my acceptance of my own trustworthiness must be based on my believing myself to be reliable in my acceptances. And this kind of belief cannot bootstrap itself into the status of a keystone of reason.

Acknowledgments I would like to thank Guido Melchior and Martina Fuerst for their invitation at the Lehrer workshop in Graz in 2011 where a version of this article was read, and for their patient editorial work. I thank a referee of this article for his or her very helpful comments, hoping that I have taken them enough into account, and the participants for their reactions. Finally, I thank Keith Lehrer, for his generosity and for his teachings over the years.

\section{References}

Barnes, J. (1982). The beliefs of a Pyrrhonist. Proceeding of the Cambridge Philological Society, 28, $1-28$.

\footnotetext{
${ }^{8}$ David (1991) raises the concern that Lehrer's view might be closer to reliabilism than he is prone to admit.

${ }^{9}$ It is interesting to note that similar difficulties affect Crispin Wright's recent attempt to solve the sceptical problem by appealing to the notion of trust and of "entitlement" on the basis of the attitude of acceptance (Wright 2004).
} 
Bayne, T., \& Pacherie, E. (2005). In defence of the doxastic conception of delusion. Mind and Language, 20(2), 163-188.

Bratman, M. (1992). Practical reasoning and acceptance in a context. Mind, 102, 1-15.

Carruthers, P. (2012). The fragmentation of reasoning. In P. Quintanilla (Ed.), La coevolución de mente y lenguaje: Ontogénesis y filogénesis. Lima: Fondo Editorial de la Pontificia Universidad Católica del Perú.

Cohen, L. J. (1989). Belief and acceptance. Mind, 98, 367-389.

Cohen, L. J. (1992). An essay on belief and acceptance. Oxford: Oxford University Press.

Currie, G. (2000). Imagination, delusions and hallucination. In M. Davies \& M. Coltheart (Eds.), Pathologies of belief (pp. 167-182). Oxford: Blackwell.

Currie, G., \& Ravencroft, I. (2002). Recreative minds. Oxford: Oxford University Press.

David, M. (1991). On the roles of trustworthiness and acceptance. In Brandl, J., Gombocz, W., \& Piller, C. (1991). Metamind, knowledge and coherence, Essays on Keith Lehrer. Grazer Philosophische Studien, 40, 93-107.

Dennett, D. (1978). Brainstorms. Cambridge: MIT Press.

Engel, P. (1998). Believing, accepting, and holding true. Philosophical Explorations, I(2), 140-151.

Engel, P. (1999). Dispositional belief, assent, and acceptance. Dialectica, 53(3-4), 211-226.

Engel, P. (Ed.). (2000). Believing and accepting. Dordrecht: Kluwer.

Engel, P. (2008). Belief and normativity. Disputatio, 2(23), 153-177.

Evans, J., \& Frankish, K. (Eds.). (2008). In two minds, dual processes and beyond. Oxford: Oxford University Press.

Fodor, J. (1983). The modularity of mind. Cambridge: MIT Press.

Frankish, K. (2004). Mind and supermind. Cambridge: Cambridge University Press.

Frede, M. (1987). The sceptic's two kinds of assent. In Essays in ancient philosophy. Minneapolis: University of Minnesota Press.

Gendler, T. (2000). Belief and alief. Journal of Philosophy, 105(10), 634-663.

Koriat, A. (2000). The feeling of knowing. Consciousness and Cognition, 9, 149-171.

Lehrer, K. (1983). Belief, acceptance and cognition. In H. Parret (Ed.), On believing (pp. 172-183). Berlin: De Gruyter.

Lehrer, K. (1990a). Theory of knowledge. Boulder: Westview. (quoted after the second edn. 2000).

Lehrer, K. (1990b). Metamind. Oxford: Oxford University Press.

Lehrer, K. (1997). Self-trust: a study of reason, knowledge and autonomy. Oxford: Oxford University Press.

Lehrer, K. (2000). Belief and acceptance revisited. In P. Engel (Ed.), Believing and accepting (pp. 209-220). Dordrecht: Kluwer.

Lehrer, K. (2003). Replies. In E. Olsson (Ed.), The philosophy of Keith Lehrer (pp. 309-356). Dordrecht: Springer.

Lycan, W. (1985). Tacit belief. In R. Bogdan (Ed.), Belief (pp. 61-82). Oxford: Oxford University Press.

Pacherie, E. (2000). The content of intentions. Mind and Language, 15(4), 400-432.

Radford, C. (1975). How can we be moved by the fate of Anna Karenina? Proceedings of the Aristotelian Society, 49, 67-80.

Scanlon, T. (1998). What we owe to each other. Cambridge: Harvard University Press.

Schwitzgebel, E. (2001). In between believing. Philosophical Quarterly, 51, 76-82.

Searle, J. (1983). Intentionality. Cambridge: Cambridge University Press.

Shah, N., \& Velleman, D. (2005). Doxastic deliberation. Philosophical Review October 2005, 114(4), 497-534.

Sperber, D. (2001). In defense of massive modularity. In E. Dupoux (Ed.), Language, brain and cognitive development: essays in honor of Jacques Mehler (pp. 47-57). Cambridge: MIT Press.

Stalnaker, R. (1984). Inquiry. Cambridge: MIT Press.

Stich, S. (1978). Beliefs and subdoxastic states. Philosophy of Science, 45, 499-518.

Velleman, D. (2000). On the aim of belief. In The possibility of practical reason (pp. 244-281). Oxford: Oxford University Press.

Wright, C. (2004). Warrant for nothing (and foundations for free)? Proceedings of the Aristotelian Society, 78, 167-212. 